\title{
Violência e satisfação com a democracia no Brasil
}

\author{
Marcio de Lucas Gomes \\ Jakson Alves de Aquino
}

\section{Introdução ${ }^{1}$}

A violência é uma das grandes temáticas do cotidiano da sociedade brasileira. Embora não esteja no rol dos países que vivenciam conflitos militares, o Brasil possui uma das mais altas taxas de homicídio do mundo, estando, assim, como outros países da América Latina, na contramão da tendência mundial de redução do número de homicídios, alcançando o recorde de 59.627 homicídios, representando uma taxa de 29,1 mortes por 100 mil habitantes em 2014, segundo a série histórica registrada pelo Atlas da Violência (Cerqueira et al., 2016). O Brasil também possui sistemas policial e judiciário pouco eficientes, com baixa taxa de conclusão de processos, o que gera uma sensação de impunidade por parte da população. Segundo levantamento realizado pela Comissão Nacional de Justiça (CNJ)2 , em 2017, com base em dados de 2016, apenas 27\% de todos os processos foram solucionados, o que significa que, mesmo sem novas demandas, os tribunais brasileiros levariam aproximadamente 2 anos e 8 meses para emitir todas as sentenças pendentes, o que indica baixo desempenho em comparação com sistemas penais de porte semelhante (Adorno, 1994).

Observando a série temporal entre 2007 e 2014 dos dados do Barômetro das Américas $^{3}$ para o Brasil, encontramos uma nova evidência da magnitude da violência enquanto fenômeno social. A violência é apontada pelos entrevistados como o problema mais grave pelo qual o país está passando. Na Figura 1, observamos que, durante esse período, essa variável apresentou valores percentuais mais elevados do que os relacionados a problemas econômicos, o segundo tipo mais citado ${ }^{4}$. A partir de 2010, há

\footnotetext{
${ }^{1}$ Somos gratos aos revisores anônimos pelas sugestões de melhoria no artigo, especialmente pela orientação de usar modelos de equações simultâneas e modelos de mediação causal, o que permitiu uma discussão mais aprofundada dos resultados e evitou que cometêssemos erros graves. Agradecemos também à Fundação Cearense de Apoio ao Desenvolvimento Científico e Tecnológico (Funcap) pela bolsa de pesquisa do primeiro autor.

${ }^{2}$ Cf.: <http://www.cnj.jus.br/files/conteudo/arquivo/2017/09/e5b5789fe59c137d43506b2e4ec4ed67.pdf>. Acesso em: 3 abr. 2018.

3 Os dados do Barômetro das Américas (AmericasBarometer) são obtidos a partir de surveys conduzidos pelo Latin American Public Opinion Project (Lapop), da Vanderbilt University. A primeira onda do Barômetro das Américas no Brasil foi realizada entre 12 de julho e 26 de agosto, como parte da onda de surveys Lapop AmericasBarometer 2006-2014. Somos gratos ao Lapop e a seus apoiadores por tornarem os dados disponíveis. Disponível em: <https://www.vanderbilt.edu/lapop/data-access.php>. Acesso em: 3 abr. 2018. 4 Os problemas associados à violência foram codificados a partir das respostas que correspondiam às categorias: "Delinquência, crime, violência", "Narcotráfico", "Conflito armado", "Segurança (falta de)", "Violência", "Impunidade", "Sequestro", "Gangues"; ao passo que os problemas associados à economia
} 
um sinal de queda nesses dois índices, porém entre 2012 e 2014 há uma elevação expressiva para o relacionado à violência, enquanto aquele associado à economia mantém a tendência de queda, indicando uma preponderância ainda maior do tema em anos recentes.

Figura 1

Maior problema do país segundo os brasileiros - 2006-2014 (\%)

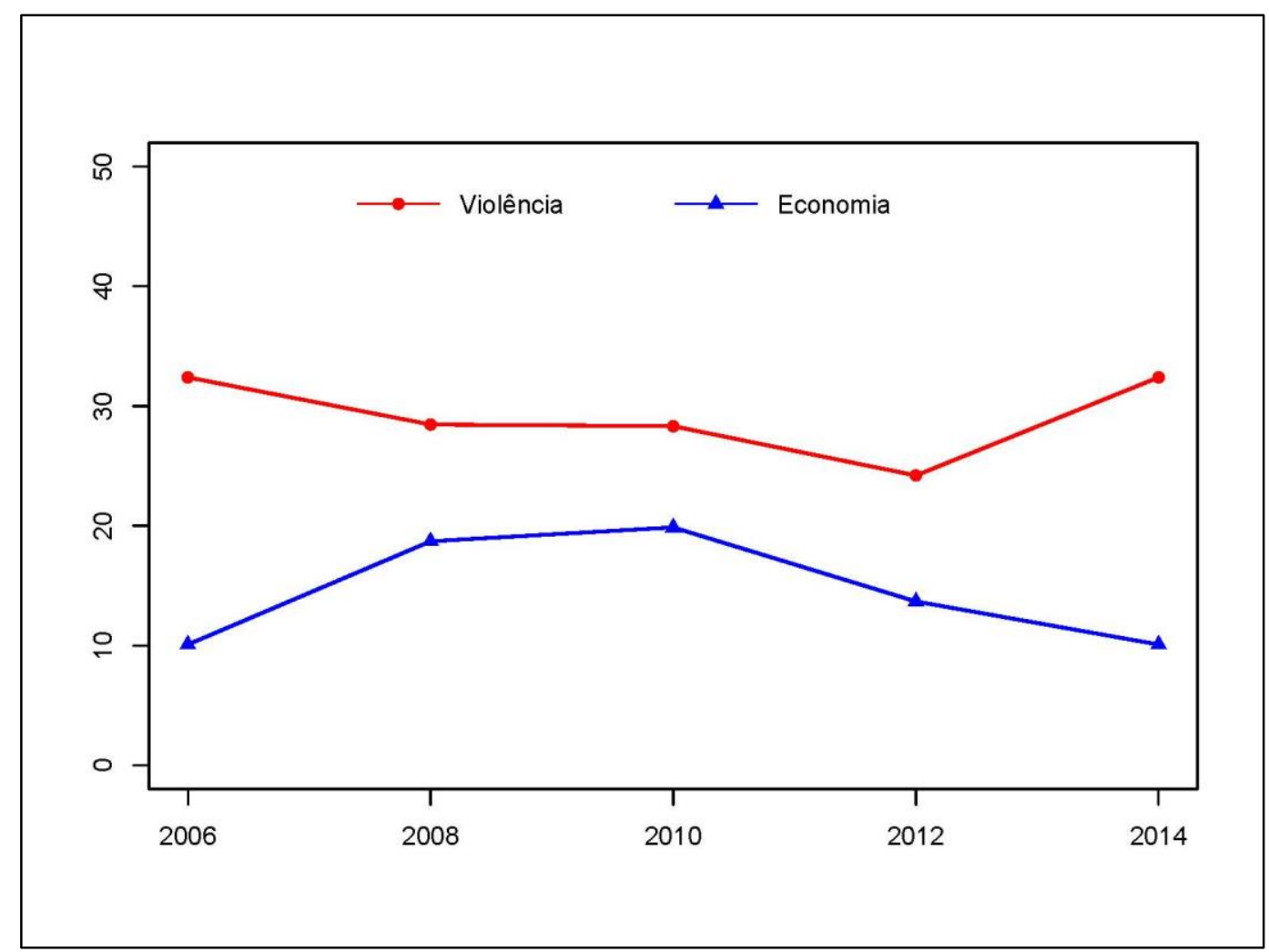

Fonte: Barômetro das Américas.

A percepção da violência como problema mais grave do país afeta a visão que os brasileiros têm sobre o funcionamento do regime democrático no Brasil. Neste artigo, analisamos os impactos de variáveis relacionadas à violência e ao crime sobre a satisfação com a democracia a partir de dois aspectos: um instrumental e outro cultural. Por um lado, a vitimização pela violência acarreta custos socioeconômicos para os cidadãos, assim como desconfiança na capacidade que as instituições do regime democrático têm de protegê-los. Diante desse cenário, os indivíduos manifestariam rejeição ou indiferença em relação à democracia. Por outro lado, a ausência de controle sobre o crime gera a proliferação de

correspondiam a: "Economia, problemas com, crise de", "Altos preços", "Desemprego/falta de emprego", "Pobreza", "Favelas". 
não cooperadores, pois, uma vez que as pessoas se sentem inseguras quanto aos outros ao seu redor, desencadeia-se um efeito cascata: a partir da desconfiança individual, a confiança interpessoal na sociedade é corroída e, consequentemente, as possibilidades de as pessoas disporem-se a empregar tempo e recursos em ações coletivas que possam prover bem público, fundamental como base comportamental da democracia. A violência, portanto, minaria a democracia pelo menos de duas formas: ao levar as pessoas a não acreditarem na capacidade do regime de protegê-las e ao reduzir a confiança interpessoal.

\section{Confiança e cooperação}

Aristóteles, em seu livro $A$ política, escreveu a famosa frase "O homem que vive só é um Deus ou uma besta". Segundo o autor, a atividade de mediar interesses privados na esfera pública, para a qual deu o nome de política, é o que distingue as pessoas de outros seres. Nas dezenas de Constituições existentes nas cidades-Estado independentes da Grécia que foram analisadas no decorrer dessa obra, o estabelecimento de acordos coletivos é uma das principais características comuns a elas. Tal ideia representa um dos primeiros esforços de construção de uma teoria dos grupos sociais, ou seja, uma resposta para a pergunta "por que os indivíduos se unem em coletividades?".

Entre os seres humanos a interação social não é apenas artifício importante para sua sobrevivência, mas também elemento constitutivo da sua humanidade. Esse aspecto fundamental dos fenômenos humanos põe em questão duas dimensões da vida social: por um lado, as pessoas possuem percepções de risco, avaliações de custo e desejos subjetivos individuais; por outro, elas dependem da vontade e da ação de outras pessoas para conseguir informação e recursos necessários para a obtenção de um benefício.

Partindo desse pano de fundo, cabe mencionar que a confiança é um dos fatores mais importantes para a cooperação. A confiança interpessoal pode ser definida como a percepção de uma pessoa de que existe uma probabilidade favorável de receber ajuda ou colaboração espontânea de outra. Também existe confiança quando, numa interação prolongada entre dois indivíduos, estes consideram pequeno o risco de trapaça por parte de um deles. $O$ espectro da confiança pode variar entre a total descrença, em que a pessoa não tem nenhuma expectativa de haver cooperação, e a obrigatoriedade, na qual há certeza de que a conduta será realizada (Lundåsen, 2002).

Além disso, cabe ressaltar o processo de habituação do comportamento humano. A experiência individual de conviver com muitos cooperadores induz uma atitude mais favorável à confiança, visto que os ganhos advindos da cooperação são maiores e a memória de sucesso nas interações favorece a aposta nessa estratégia por indução simples: "se confiar tem dado certo, então dessa vez também dará". Dessa forma, a confiança interpessoal assume duas dimensões básicas: por um lado, um aspecto que corresponde às características individuais, dado que indivíduos são mais ou menos 
cooperadores e, por outro, um aspecto que faz referência às propriedades coletivas de uma comunidade, as quais consistem na maior ou menor presença de estímulos à cooperação.

Em decorrência disso, a confiança interpessoal possui um aspecto instrumental importante: a ação de agir em cooperação com outros é um processo que forma laços comunitários, os quais permitem que uma coletividade aja para realizar algo de maior magnitude, que ninguém seria capaz de realizar individualmente, embora seja do interesse de todos. Outra implicação é que a cooperação entre os indivíduos, além de resolver problemas pontuais comuns, também tem o potencial, a longo prazo, de se tornar um modelo de como coordenar ações coletivas. Regras coletivas são fundamentais em grupos maiores de pessoas por serem capazes de promover fiscalização e coerção da ação de aproveitadores (indivíduos que não cooperam para a produção do bem mas usufruem dele), resolvendo parte do problema da ação coletiva apontado por Olson (1999). Lochner, Kawachi e Kennedy (1999), em revisão bibliográfica sobre o tema, também apontaram que níveis mais elevados de confiança interpessoal possuem efeito negativo sobre as taxas de mortalidade, o número de mortes violentas e a delinquência. Índices mais completos de medição de confiança interpessoal também foram relevantes para a explicação do controle social informal da comunidade, uma vez que vizinhanças mais comunitaristas apresentam menor frequência de brigas, pichações e desrespeito a adultos por parte de crianças.

Buscando entender quais características dos agentes são favoráveis e quais são desfavoráveis à cooperação, Axelrod e Hamilton (1981) testaram diversos modelos baseados em agentes (MBAs) - algoritmos computacionais construídos com propriedades específicas que interagem num universo virtual que simula condições da realidade - a fim de verificar qual deles seria mais eficiente num jogo simples de cooperação e, portanto, alcançaria maior sucesso reprodutivo, tornando-se predominante com o tempo. A tarefa consistia em acumular pontos em uma sequência de rodadas no jogo Dilema do Prisioneiro 5 . O modelo mais eficiente foi o Tit-for-Tat, o qual consistia em agir segundo a lei "olho por olho, dente por dente". O algoritmo iniciava cooperando, de forma altruísta, e agia na rodada seguinte rigidamente segundo o resultado da rodada anterior: cooperava quando cooperavam, desertava quando desertavam. Além disso, MBAs altruístas apresentaram médias maiores que desertores, exceto na situação em que no estado inicial havia maior quantidade de MBAs desertores.

Apesar da complexidade reduzida dos MBAs, os resultados de Axelrod e Hamilton são relevantes para entendermos a dinâmica social de formação e destruição da confiança. Algoritmos definidos de forma a apostar no altruísmo tenderam ao sucesso pelo fato de a cooperação gerar mais benefícios que a deserção. Apenas quando o mundo virtual era iniciado com quantidade maior de agentes seguindo estratégias desertoras, cooperar tornava-se uma cilada para os altruístas: cooperando com desertores, suas perdas são

${ }^{5} \mathrm{O}$ Dilema do Prisioneiro é um jogo que se baseia na situação hipotética de dois prisioneiros que não podem se comunicar e têm de decidir por delatar o crime que os dois cometeram ou se omitir. 
crescentes porque a probabilidade de encontros com agentes cooperadores é muito reduzida.

Consequentemente, existem duas situações de equilíbrio: uma de cooperação generalizada (mundo dominado por estratégias altruístas) e outra de não cooperação generalizada (dominada por estratégias egoístas). Por um lado, isso implica que fatores externos podem influenciar no equilíbrio, como um grupo de desertores que têm o potencial de destruir a confiança numa população, na medida em que induzem comportamentos de autoproteção. Por outro lado, estratégias mais altruístas são capazes de romper o equilíbrio e gerar cooperação, apesar de continuarem sendo sensíveis a desertores. Ohtsuki et al. (2006), utilizando a mesma metodologia, concluíram, ainda, que em arranjos espaciais nos quais agentes interagem com maior número de outros agentes os benefícios são pouco superiores aos custos desmobilizam a cooperação.

Modelos baseados em agentes, computacionais ou não, como aponta Dawkins (1976), são experimentos teóricos que têm o potencial de elucidar fenômenos conhecidos, mas mal compreendidos. Mesmo não intencionais, ações podem aproximar-se de modelos matemáticos, não porque foram realizadas a partir de cálculos sofisticados, mas porque as ações que são mais efetivas e se tornam comuns são justamente aquelas que se aproximam de cálculos sofisticados.

Tomando uma sociedade hipotética como exemplo, a predominância do perfil desertor de seus cidadãos tende a gerar maior confiança entre membros de subgrupos, como famílias e territórios, e menor confiança nas pessoas em geral, as quais fazem parte de outros agrupamentos. Consequentemente, esperam-se alta cooperação em cada clivagem e baixa cooperação generalizada, o que implica disputas por recursos, nas quais um grupo busca conquistar a propriedade do outro. A situação de competição generalizada, sem acordos comuns preestabelecidos, tem como produto uma desigualdade radical de recursos, uma vez que os ganhadores da "primeira rodada" utilizam sua vantagem para vencer as próximas disputas, acumulando mais e mais recursos.

Argumentando sobre os efeitos da cooperação e da competição nos sistemas sociais, Coleman (1994) aponta que uma relação entre duas pessoas na qual existe uma diferença substantiva de recursos implica poder assimétrico de definir o resultado da interação, ou seja, aqueles que possuem mais tendem a ganhar mais na relação. E este é o produto das relações hierárquicas: uma elite que assume grande poder decisório nas dinâmicas sociais, manipulando sistemas políticos e econômicos de acordo com seu interesse, a fim de se perpetuar no poder. Assim, como expomos em nosso exemplo hipotético, atores políticos que disputam espaços em instituições tendem a usá-las em favor de seu grupo. Na tendência oposta, uma sociedade de cooperadores maximizaria sua capacidade de produção num jogo de soma diferente de 0 , uma vez que todos estariam dispostos a dividir os esforços para obtenção do bem público. Nesse exercício, conseguimos identificar os dois polos da dinâmica de cooperação e concebemos que as sociedades se localizam no intervalo desse espectro. 
Porém, não devemos conceber a confiança interpessoal e a cooperação apenas em seu aspecto individual. Giddens (1989) e Bunge (2000) explicam o potencial que as relações sociais têm de se consolidar em instituições ou sistemas, descrevendo a mudança social como o processo no qual comportamentos emergem e se generalizam, tornando-se habituais, uma vez que passam do nível reflexivo, racionalizado, para a forma pré-reflexiva ou naturalizada, na qual os atores os replicam espontaneamente. Na etapa subsequente, os comportamentos são transmitidos intergeracionalmente, por meio da socialização das crianças, sendo internalizados como regras e utilizados como ferramentas para a vida social. Desse modo, atingem uma dimensão estruturante - externa e coercitiva aos indivíduos - em que a solução hierárquica assume status eletivo de resolução mais simples ou mais tradicional. Ou seja, numa sociedade com predomínio de relações hierárquicas, resolver impasses por meio do conflito, descartando as possibilidades de negociação, parece, para seus membros, intuitivamente a melhor alternativa para grande parte das situações da vida social.

O predomínio de um certo tipo de relação para resolver conflitos impacta diretamente o caráter do sistema político, pois regimes democráticos e autoritários podem ser entendidos como as formas institucionais dos dois tipos de equilíbrio, o cooperativo e o de deserção. De acordo com Reis (2003, p. 37):

O arranjo autoritário é um "círculo vicioso" porque o precedente da afirmação violenta do poder inibe a disseminação de comportamentos mais cooperativos no interior da população. A vontade do poderoso de plantão prevalece em última instância, dificultando o estabelecimento de laços "horizontais" de confiança mútua e tornando inúteis, por pouco confiáveis, compromissos que envolvam compensações futuras.

Dessa forma, o autoritarismo pode ser entendido não apenas como resultado de uma desconfiança generalizada por parte dos cidadãos que impede a formação de associações civis, uma vez que desestimula o engajamento em organizações nas quais recursos privados são alocados coletivamente, mas também como um dos fatores de manutenção dessa percepção hostil. Líderes autoritários controlam os recursos da sociedade e tanto têm meios para oferecer suporte aos seus apoiadores em conflitos militares ou ideológicos como podem punir dissidentes em relação ao seu domínio, alocando de maneira pessoal recursos de toda a sociedade.

No livro Making democracy work, Putnam (1994) argumenta que atitudes políticas tendem a ser replicadas nas próximas gerações, criando, assim, uma persistência da trajetória, ou seja, um comportamento político constituído tende a impactar o desenvolvimento futuro de um país. No caso empírico abordado pelo autor, as regiões Norte e Sul da Itália foram classificadas em níveis distintos de civismo - participação de organizações civis - entre seus habitantes, sendo o Norte detentor de maior civismo, portanto, mais favorável à adoção de instituições burocráticas que o Sul, o que gerou, 
segundo Putnam, diferenças significativas nos resultados do projeto de autonomização das províncias por parte do governo federal, que consistia na implementação de um mesmo modelo institucional em todas as províncias, com o Norte apresentando melhor desempenho.

Contudo, não devemos perder a visão do espectro contínuo entre cooperadores ideais e não cooperadores ideais, tal como para os níveis de democracia e autoritarismo. Baquero (2003) aponta que as democracias na América Latina têm passado, nas últimas duas décadas, por uma corrosão das associações em que predominam relações interpessoais horizontais, que ajudavam a canalizar as demandas sociais por vias democráticas. Os produtos disso são um modelo de democracia delegativa, caracterizada por uma relação vertical entre presidente e eleitores, tendo como praticamente único mecanismo de controle popular do governo a eleição presidencial, e redes de dominação populista, nas quais a oferta de benesses alimenta um círculo no qual o patriarca se apresenta como o provedor das soluções e a cooperação é inibida.

Assumimos, portanto, que a democracia possui bases socioculturais, fundamentadas em atitudes e comportamentos dos cidadãos, e que um dos seus elementos, a eficiência das relações sociais, depende da horizontalidade das relações e da confiança interpessoal. Por haver grande desconfiança na sociedade, sistemas que funcionam para coordenar a ação coletiva, como a democracia, soarão, para um cidadão mediano, como empreendimentos nos quais o retorno de tempo e recursos será baixo, uma vez que ele suspeita da existência de grande número de aproveitadores. No lado oposto, níveis de confiança elevados não apenas permitem facilidade no surgimento de organizações no seio da sociedade civil como também propiciam a perspectiva da democracia como um jogo de soma diferente de zero, sendo potencialmente boa para todos.

\section{A dimensão instrumental e os benefícios do regime}

Segundo Easton (1968), o sistema político se mantém porque as pessoas obedecem, e elas obedecem quando o sistema é visto como legítimo. Easton classificou os tipos de apoio ao sistema em difuso e específico. O apoio difuso seria constituído por sentimentos de legitimidade e submissão que fazem os membros de um sistema o apoiar mesmo que não estejam sendo especialmente beneficiados por ele, enquanto o apoio específico pode ser entendido como a satisfação com o funcionamento atual do sistema. Uma insatisfação prolongada poderia corroer a legitimidade do sistema.

Se, por um lado, a democracia é condicionada pelas atitudes dos seus cidadãos, por outro, essas atitudes dependem, pelo menos em parte, dos benefícios proporcionados pelo regime político. Cheibub et al. (1996) encontraram evidências de que países que estão em trajetória de crescimento econômico possuem menor probabilidade de sofrer transições de regime, seja este democracia ou ditadura. Roemer (1995) apontou que o apoio à 
democracia, sobretudo da parcela mais pobre da população, é sensível ao grau de incerteza sobre o futuro econômico, sendo que o grau dessa incerteza depende do grau de imprevisibilidade sobre qual política econômica será adotada após as eleições. Essas conclusões sugerem que um regime com maior aporte de recursos socioeconômicos tende a dissuadir insatisfação política ao ofertar incentivos diretos para o apoio da população, gerando um consenso baseado no ganho individual por parte dos cidadãos.

Levando em consideração uma situação inversa, Moisés (1995) destacou as dificuldades enfrentadas pelas nações da América Latina na implementação da democracia. Com a maior liquidez econômica mundial, a competição nos mercados de capital tornou-se mais feroz, reduzindo as possibilidades de adotar medidas de valorização do salário mínimo e reconhecimento de direitos trabalhistas, o que acentua a desigualdade econômica e restringe a elevação da qualidade de vida das camadas de menor renda da população. Além disso, a inserção de um novo ator político com poder de veto, os grandes conglomerados empresariais, promoveu novas assimetrias de representação política. Moisés argumenta, ainda, que o menor aporte de recursos tem um impacto diferente nas democracias: nas mais velhas, reduz a aprovação do governo, ao passo que nas mais novas tem potencial para trazer à tona uma memória autocrática, uma vez que as bases socioculturais do regime, as quais envolvem a socialização dos cidadãos na cultura democrática, são incipientes.

Casalecchi (2016) também argumentou sobre o efeito potencial das condições socioeconômicas na opinião dos cidadãos. Revisando bibliografia que utiliza variáveis do nível individual para medir a consistência do apoio à democracia, esse autor apontou que as pesquisas tendem a captar uma diferença significativa entre a preferência pela democracia e a preferência pela democracia em situações adversas. Questionários que incluem um simples experimento mental, no qual se pede aos entrevistados que suponham um contexto de incapacidade do governo em reduzir o desemprego, a criminalidade e a corrupção, por exemplo, captam uma queda do número daqueles que dizem preferir a democracia ao autoritarismo. Além disso, com base em dados do Barômetro das Américas, Casalecchi também aponta que a adesão à democracia por parte dos latino-americanos tende a ser difusa. Ao passo que 75,9\% afirmam apoiar a democracia e 77,0\% aderem às eleições, apenas $42,3 \%$ possuem compromisso com a democracia, ou seja, rejeitam ditaduras mesmo em situações adversas. Tais evidências corroboram a hipótese de que condições socioeconômicas e satisfação com a democracia estão fortemente relacionadas, uma vez que a opinião pública atribui grande importância aos benefícios públicos no julgamento do sucesso do regime.

A influência dos fatores socioeconômicos, todavia, não se restringe apenas à avaliação direta do regime. Lipset (1959) foi um dos primeiros a apresentar dados empíricos acerca da relação entre níveis elevados de (1) desenvolvimento e (2) democracia, na medida em que os países que possuíam uma das características também tendiam a possuir a outra. O estudo, que não traz inferências sobre causalidade, contudo, 
faz parte da literatura que assume como referência teórica a influência positiva de (1) sobre (2), denominada teoria da modernização. A narrativa sociológica que explicava esse processo foi inicialmente descrita por Weber (2004), ao indicar que o advento do capitalismo coincidia com o ethos do trabalho presente em países majoritariamente protestantes. Segundo o autor, a mudança nas relações de trabalho é uma das implicações de uma mudança comportamental mais ampla. Uma vez que um novo contexto social surge, os valores dos indivíduos adaptam-se à realidade emergente e novas prioridades de alocação de tempo e recursos são estabelecidas por eles.

Mais recentemente, Inglehart e Welzel (2009) puderam testar de forma ampla a teoria da modernização com os dados de quatro ondas de aplicação da Pesquisa Mundial de Valores ${ }^{6}$, realizando uma inferência causal sobre o processo. De acordo com os autores, o desenvolvimento socioeconômico interfere na mudança cultural na medida em que o estoque disponível de recursos na sociedade se eleva. Isso propicia alívio na pressão por sobrevivência de uma maior camada da população e condições mais propícias para a expansão dos gastos públicos médios em áreas sociais, elevando a escolarização, com impactos econômicos e culturais ainda maiores para as novas gerações. Por sua vez, níveis de escolaridade mais altos permitem a construção de pensamentos mais abstratos e uma compreensão de demandas que transcendem os indivíduos e seus círculos de conhecidos próximos. Os resultados revelaram que os países com maior crescimento do PIB per capita apresentaram valores mais elevados para o índice de autoexpressão, associados à tolerância, ao reconhecimento da importância do estímulo à criatividade das crianças e à liberdade individual, que impactam positivamente o apoio à democracia.

Vale ressaltar, ainda, que o processo de modernização não é linear e que a construção de valores pró-democráticos é sensível ao modo pelo qual um novo aporte de recursos para a sociedade, advindo de um período de crescimento econômico, será distribuído. Welzel, Inglehart e Kruse (2017) apontam que a mudança nas instituições políticas ocorre num ritmo em que períodos duradouros de estabilidade são interrompidos por transições de regime e, no intervalo entre as transições, há um espaço para que outras variáveis catalisem ou inibam o processo. Assim, um curto período de crescimento econômico tende a impactar positivamente as avaliações do governo ao passo que um longo período de crescimento favorece a consolidação da democracia. Em um estudo de caso que ilustra o fenômeno, Wilson (1995) aponta que o desenvolvimento econômico vivenciado pela África do Sul durante as décadas de 1940 a 1990 beneficiou a população branca do país ao mesmo tempo em que impactou negativamente as condições gerais da população negra, uma vez que a implementação de novas tecnologias na produção aniquilou a agricultura de pequeno porte. Esse processo, sustentado pelas políticas de apartheid e pela história pregressa de colonialismo, gerou grandes desigualdades sociais e políticas, semelhantes às que ocorreram com a "privatização pelo topo" feita por Boris

${ }^{6}$ Disponível em: <http://www.worldvaluessurvey.org>. Acesso em: 16 mar. 2018. 
VIOLÊNCIA E SATISFAÇÃO COM A DEMOCRACIA NO BRASIL

Yeltsin na Rússia pós-soviética, como aponta Brus (1995). No primeiro caso, os resultados positivos da modernização concentraram-se na população branca e, no segundo, entre o empresariado que mantinha relações corruptas com o governo soviético e tinha acesso a informações privilegiadas numa sociedade fechada.

\section{A percepção da violência}

Com base nos elementos expostos nos parágrafos anteriores, podemos afirmar que existe relação entre percepção da violência e sensação de segurança e satisfação com a democracia? Fernandez e Kuenzi (2010, p. 463) apresentaram evidências de que, em países com taxa de criminalidade elevada, as pessoas que se sentem mais seguras são mais satisfeitas com a democracia. Por um lado, o combate ao crime deve ser um componente importante na avaliação da eficiência das instituições públicas, uma vez que afeta diretamente a percepção dos cidadãos de estar sob ameaça. Por outro, aqueles indivíduos que cometem crimes agem como não cooperadores no conjunto das interações sociais, e tendem a induzir, no resto da população, a sensação de que as pessoas não são confiáveis. Cabe apontar, contudo, que o maior impacto da violência não se dá pela experiência individual que pessoas tiveram com o crime, mas pelos efeitos indiretos da violência, como a propagação do medo e a socialização de crianças e adolescentes em costumes que envolvem a proteção contra ameaças.

Paiva (2014) argumenta que crimes violentos, tais como mortes calvário, aquelas que provocam grande comoção social, têm o potencial de gerar um clamor contestatório da ordem social, pois são vistas como atentado contra as regras e os valores naturalizados pelo comportamento cotidiano. E apesar de todos os crimes, mesmo os mais simples, serem contrários aos valores que compõem a sociedade brasileira, os casos analisados pelo autor - a morte do jornalista Tim Lopes em junho de 2002 e a de João Hélio em março de 2007 - despertaram grande comoção da população, distinguindo-se por angariarem grande espaço na mídia e terem se constituído uma representação social da crueldade. Os crimes possuíram traços que subvertem aspectos fundamentais da moralidade brasileira de influência cristã, levando-os a incorporar as narrativas de martírio e redenção.

Esse fenômeno das mortes calvário contrasta com a situação cotidiana dos habitantes da Zona da Mata de Minas Gerais etnografada por Comerford (2014). Na narrativa desse autor, apesar dos indicadores objetivos da alta frequência com que esses moradores lidavam com experiências violentas e tensões, cuidadosamente geridas por meio do que chamou de sociabilidade agonística, estes não revelaram sensação de insegurança nos primeiros contatos.

A interpretação de Comerford é de que a violência é internalizada pelo costume e pela socialização de tal forma que dificilmente é reelaborada racionalmente pelos moradores quando questionados sobre o perigo do lugar. Adorno (1994) encontrou resultados semelhantes ao analisar 297 processos penais, instaurados e julgados na capital 
de São Paulo, entre os anos de 1984 e 1988. As testemunhas em audiências apresentavam relatos que descreviam cenas de grande violência com parcimônia e naturalidade, o que ele identificou como banalização da violência.

Esse aparente paradoxo - que nos leva a crer que a percepção de segurança não mantém uma relação direta com as taxas de criminalidade - se dissolve quando levamos em consideração as características cognitivas humanas. Tversky e Kahneman (1973) e Slovic, MacGregor e Kraus (1987) apontaram que a percepção da frequência de um evento está diretamente ligada a determinados elementos heurísticos, utilizados como estimativas para a avaliação do perigo. Eventos raros, mas marcantes, como um acidente nuclear, são considerados de maior risco que eventos mais cotidianos. Num dos experimentos clássicos repetidos por Tversky, a estimativa que as pessoas fazem do cálculo do produto da sequência dos dez primeiros números naturais $(1,2,3 \ldots 10)$ se altera sensivelmente de acordo com o sentido da sequência (crescente ou decrescente) dos números visualizada pelo entrevistado. Visualizar inicialmente os números menores gera a sensação de resultado menor do que a situação contrária. Com base nisso, Pinker (2013) afirmou que a sensação de que o século XX foi muito violento se comparado à história pregressa é, em grande parte, explicada pelas duas grandes guerras, as quais, apesar de corresponderem a um número absoluto de mortes alto, são pontos fora da curva no grande processo de pacificação iniciado no século XVII, desde quando a taxa de mortos ponderada pelo número de habitantes vem caindo consideravelmente.

Partindo disso, podemos interpretar que mortes calvário fazem parte de um tipo de crime que gera comoção nacional em grande medida por serem noticiadas e divulgadas como extraordinárias, gerando a sensação de alto nível de perigo, apesar de serem pouco frequentes. Essa relação vai ao encontro das teses que postulam uma relativa independência entre os efeitos da criminalidade e os do medo da violência. A mídia e os boatos funcionam como referências para avaliação do risco de ser vítima de crime, sendo elementos tão relevantes para a percepção de segurança e estigmatização de territórios quanto a própria experiência de ter sido vítima de violência.

Observando os dados do Barômetro das Américas relativos ao Brasil para o ano 2014, é possível encontrar evidências complementares da natureza da relação entre as variáveis. À pergunta "Você foi vítima de crime nos últimos 12 meses?", 16\% afirmaram ter sido vítima. Relacionando as variáveis vitimização individual por crime e percepção de segurança, podemos observar na Figura 2 que a proporção de pessoas que se declararam seguras ou muito seguras é bem maior entre as que não foram vítimas de crime, ou seja, a vitimização reduz a percepção de segurança. 
Figura 2

Percepção de segurança e vitimização por crime

Brasil - 2014

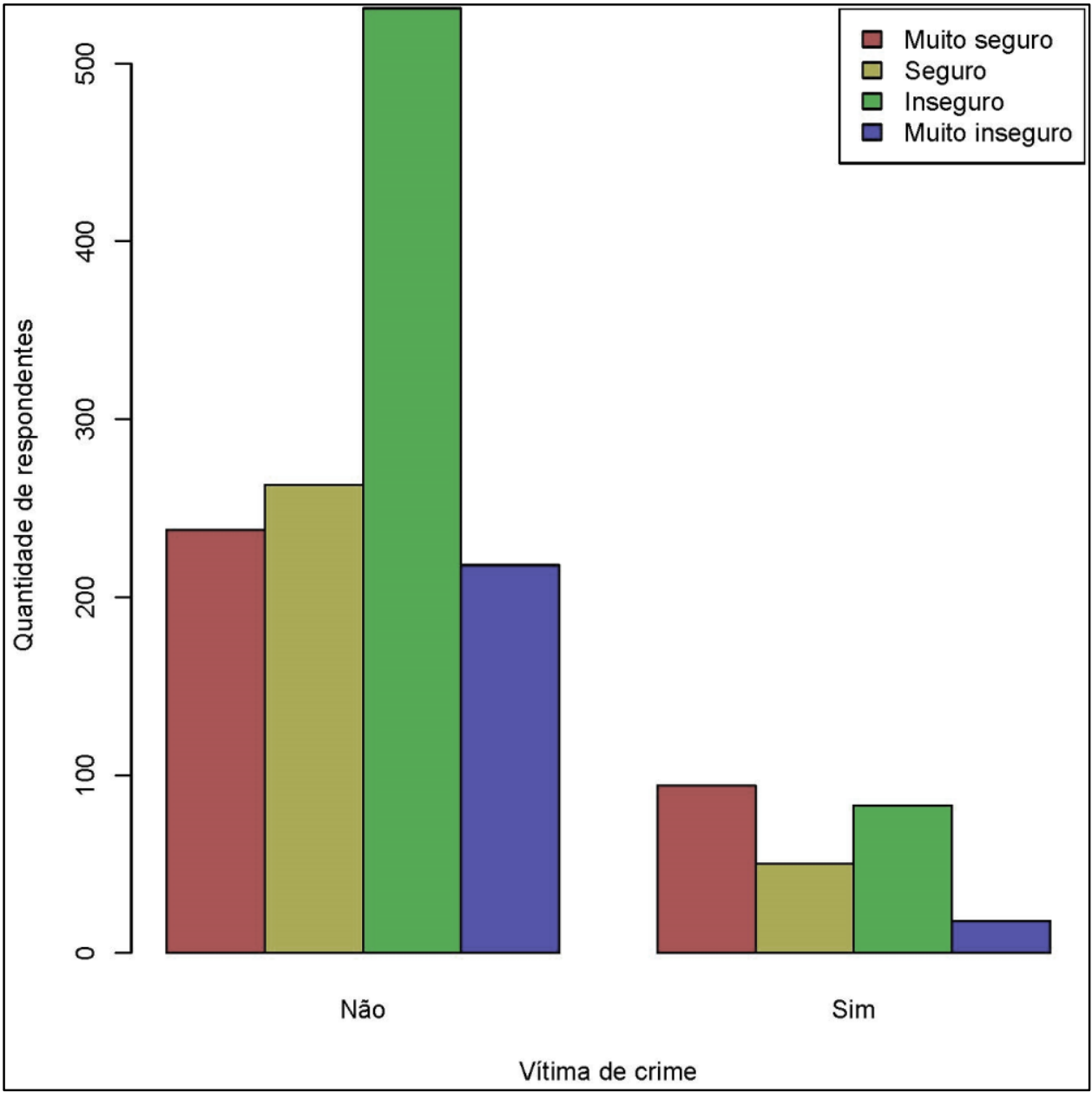

Fonte: Barômetro das Américas, Brasil, 2014.

Devemos considerar ainda uma variável criminológica importante: a punição. Becker (1968) incluiu em seus modelos a probabilidade de ser pego cometendo um crime e a de ser condenado por isso como fatores relevantes para a reincidência no crime. Levando-se em conta a curva de utilidade feita pelo indivíduo, a rentabilidade das horas empregadas no crime cresce com a redução do risco, numa relação semelhante à deserção no jogo Dilema do Prisioneiro, mencionado anteriormente. Todavia, o uso da teoria dos jogos como abordagem metodológica recebeu críticas na literatura econômica posterior a Becker, a qual descarta a racionalidade ilimitada e o conhecimento perfeito das condições de escolha como bons axiomas teóricos. Mazar, Amir e Ariely (2008) argumentam que a moralidade está relacionada também à autoavaliação que os indivíduos fazem, o que, por 
sua vez, está diretamente associado à socialização e ao comportamento dos que estão ao redor. Um dos elementos que colaboram para uma maior média de trapaça nos testes realizados pelo autor é o fato de algum outro participante, de maneira explícita, trapacear e não ser punido. Esse fenômeno revela que o comportamento dos pares é uma espécie de âncora moral que, nesse caso, gera a sensação de que trapacear um pouco não é suficiente para ser qualificado como desonesto.

Esses trabalhos convergem na explicação dos elementos que favorecem o crime, contudo acreditamos que eles dizem mais do que isso. Se as pessoas observam elementos que tornam a deserção mais atraente, é simples inferir que o comportamento delas tenderá para tal. Trata-se do que as correntes teóricas do interacionismo simbólico e os estudos recentes no campo das ciências cognitivas, como os de Tomasello (1999) e Sapolsky (2004), chamaram de teoria da mente. A habilidade em questão se refere à capacidade das pessoas de inferir quais são as intenções por trás do comportamento dos outros, estipulando como cada um agiria em um determinado contexto. As informações produzidas por esse tipo de reflexão são bastante úteis para uma pessoa se situar numa dinâmica social. No caso da criminalidade, as inferências acerca do comportamento de outras pessoas são parte importante da composição da percepção de risco, uma vez que a sensação de que o crime não é punido aumenta a expectativa de ser vítima, favorecendo o comportamento de autoproteção que desestimula a cooperação, conforme já mencionamos anteriormente.

Parte da confiança interpessoal expressa pelas pessoas advém da confiança no funcionamento das instituições em dissuadir a transgressão. Isso explica a correlação positiva, frequentemente encontrada na literatura da área, entre confiança nas instituições e confiança interpessoal. Uma vez que se tem a percepção de que as instituições públicas regulam parte das relações sociais, simetricamente, parte das precauções que deveriam ser tomadas pelos indivíduos é transferida ao Estado.

Portanto, podemos concluir que o bom funcionamento do sistema punitivo - num mecanismo post hoc, ou seja, após o acontecido - restaura a ordem social e reconstrói parte da confiança no regime em prover segurança para os cidadãos, assegurando, também, parte das expectativas que as pessoas têm sobre a possibilidade de outros trapacearem. A percepção de segurança, com isso, é mediada pela confiança na punição, uma vez que esta diz respeito aos incentivos que existem para os acontecimentos que fundamentam aquela.

\section{Dados e metodologia da pesquisa}

Nossa hipótese de partida é que as variáveis criminológicas, associadas à vitimização, têm efeito negativo sobre a satisfação com a democracia na medida em que reduzem a confiança interpessoal, a qual funciona como uma variável de mediação para a 
adesão ao regime. Para testar nossa hipótese, utilizamos os dados de 2014 do Barômetro das Américas para o Brasil.

A variável dependente foi construída a partir das respostas para a pergunta: "De uma maneira geral, você está satisfeito (...) com o funcionamento da democracia no Brasil?".

Convertemos as respostas em valores inteiros, tomando "Muito insatisfeito" como 0, num extremo, e "Muito satisfeito" como 3, no outro. O uso dessa variável se justifica pelo fato de esperarmos conseguir com ela a dimensão do apoio instrumental ao regime. Dentro do escopo teórico que assumimos, a pergunta sobre a satisfação com a democracia capta, intrinsecamente, uma avaliação que mensura custos e benefícios de apoiar o regime tendo em vista os resultados que ele produz e entrega aos cidadãos. As correlações da variável dependente com as variáveis satisfação com vida - mensurada pela pergunta "Para começar, em geral, até que ponto você está satisfeito com sua vida?" - e melhora econômica - mensurada por "Você acha que sua atual situação econômica está melhor (...) que há 12 meses?" - são significativas ao nível de $5 \%$, o que corrobora nossas expectativas.

Para mensurar confiança interpessoal utilizamos as respostas, ordenadas e convertidas para valores inteiros, para a pergunta: "Agora, falando das pessoas daqui, você diria que as pessoas daqui são (...) confiáveis?".

Essa é a única pergunta disponível no questionário que oferece algum tipo de medida da disposição atitudinal dos indivíduos para demonstrar altruísmo e cooperar.

Para as variáveis associadas a violência e vitimização, utilizamos a percepção de segurança e a vitimização individual por crime, apresentadas anteriormente, e a confiança na punição, composta das respostas para as perguntas "Você está satisfeito (...) com o trabalho da polícia no seu bairro?" e "Se fosse vítima de um roubo ou assalto, o quanto confiaria que o sistema judiciário puniria o culpado?", convertidas em variáveis numéricas e somadas para composição de um índice. Além disso, incluímos as variáveis sociodemográficas, utilizadas como variáveis de controle - sexo, idade, cor, renda e escolaridade.

A especificação do modelo principal pode ser expressa por:

$$
S_{i}=\mathrm{B}_{0}+\mathrm{B}_{1} I_{i}+\mathrm{B}_{2} P_{i}+\mathrm{B}_{3} G_{i}+\mathrm{B}_{4} V_{i}+\mathrm{B}_{5} D_{i}+\mathrm{u}_{i}
$$

em que $S$ é satisfação com a democracia, I é confiança interpessoal, $P$ é confiança na punição, $G$ é percepção da segurança, $V$ é vitimização direta por crime e $D$ é uma matriz com o conjunto das variáveis sociodemográficas - idade, sexo, renda, escolaridade e cor. Cada coeficiente $B_{i}$ consiste no efeito na média da variável dependente resultante da variação em uma unidade da variável independente e $u$ consiste na parcela aleatória do modelo, um vetor de valores que expressam a diferença entre os valores assumidos pela variável independente e o resultado da aplicação da expressão algébrica. 
A estimação dos coeficientes, contudo, possui um problema: uma vez que eles estão condicionados à unidade da variável independente, não são comparáveis uns com os outros. A fim de torná-los comparáveis, precisamos realizar sua padronização convertendo sua unidade de medida numa estatística cuja leitura seja a mesma para todas. Realizando a operação

$$
\beta=\frac{B * \sigma x}{\sigma y}
$$

que consiste na multiplicação dos parâmetros do modelo pelo desvio-padrão da variável independente associada ao parâmetro, e dividindo pelo desvio-padrão da variável dependente, temos uma nova variável que não possui unidade e tem média 0 , sendo diretamente comparável com outras variáveis padronizadas? ${ }^{7}$.

Um modelo de regressão linear com coeficientes padronizados propicia o teste da hipótese quanto a efeitos diretos de um conjunto de variáveis sobre uma variável dependente. A partir dos seus resultados, podemos mensurar a intensidade e a significância dos efeitos das variáveis criminológicas sobre a satisfação com a democracia. Todavia, na hipótese que assumimos para a dinâmica do impacto da violência sobre o apoio ao regime, consideramos, ainda, um vetor indireto de efeitos, na medida em que a sensação de insegurança gerada pelas altas taxas de criminalidade desfavorece a emergência de confiança interpessoal e, consequentemente, de adesão à democracia.

Para mensurar os efeitos indiretos das variáveis criminológicas, faremos uso de modelos de equações simultâneas (SEM), uma forma de integrar duas ou mais equações calculando os parâmetros a partir de uma minimização conjunta dos resíduos (Wooldridge, 2010). Ou seja, assumimos que a variável independente confiança interpessoal, presente na equação (1), que modela a satisfação com a democracia, é endógena, na medida em que é uma variável preditora dos valores de satisfação com a democracia e é predita por um outro conjunto de variáveis independentes - o qual inclui as variáveis criminológicas.

A equação (2) expressa o modelo cuja variável dependente é composta pela confiança interpessoal:

$$
I_{i}=\mathrm{C}_{0}+\mathrm{C}_{1} P_{i}+\mathrm{C}_{2} G_{i}+\mathrm{C}_{3} V_{i}+\mathrm{C}_{4} D_{i}+\mathrm{v}_{i}
$$

O modelo SEM tanto propicia uma estimativa robusta dos parâmetros do modelo, na medida em que contorna o problema da multicolinearidade entre as variáveis independentes, como permite que calculemos o efeito total das variáveis de interesse sobre a variável dependente principal, considerando efeitos diretos e indiretos. Estimando a

\footnotetext{
7 Para uma maior discussão sobre o procedimento de padronização dos coeficientes dos parâmetros de um modelo de regressão, consultar as notas de aula da disciplina "Sociology Graduate Statistics I", ministrada pelo professor Richard Williams, no Departamento de Sociologia da Universidade de Notre Dame. Disponível em: <https://www3.nd.edu/ rwilliam/stats1/>. Acesso em: 19 mar. 2018.
} 
equação (1), isoladamente, é esperado que o coeficiente $B_{1}$, que mensura o efeito da confiança interpessoal sobre satisfação com a democracia, seja enviesado, visto que os valores de confiança interpessoal são sensíveis às variáveis criminológicas.

Os valores preditos na equação (2) são utilizados para compor a estimação da equação (1), de forma semelhante ao procedimento realizado num modelo de mínimos quadrados em dois estágios (2SLS). Todavia, a presença de variáveis independentes iguais nos dois níveis gera uma correlação entre os resíduos $u$ e $v$, que é resolvida com base na estimação da covariância entre os dois termos ${ }^{8}$.

A partir dos parâmetros estimados, podemos calcular os efeitos totais das variáveis criminológicas sobre a satisfação com a democracia pela soma ponderada dos coeficientes. $O$ efeito direto é calculado a partir da soma simples dos coeficientes $B_{2}, B_{3}$ e $B_{4}$. Já o efeito indireto é calculado a partir da soma dos coeficientes $C_{1}, C_{2}$ e $C_{3}$ ponderados pelo coeficiente $B_{1}$. Dessa forma, os efeitos indiretos mensuram a parcela de efeito transmitido pelas variáveis criminológicas por meio da confiança interpessoal.

De forma sintética, podemos especificar o cálculo dos efeitos por:

Efeito direto $=\mathrm{B}_{2}+\mathrm{B}_{3}+\mathrm{B}_{4}$

Efeito indireto $=\mathrm{B}_{1} *\left(\mathrm{C}_{1}+\mathrm{C}_{2}+\mathrm{C}_{3}\right)$

Efeito total $=$ efeito direto + efeito indireto

O uso de modelagem SEM permite identificar os efeitos das variáveis criminológicas mediados pela confiança interpessoal, contudo, ainda tem algumas limitações. Como argumentam Imai, Keele e Tingley (2010), a mediação causal descrita a partir do uso de SEM lineares é passível de duas críticas fundamentais: não produzem uma descrição generalista da mediação causal, na medida em que (a) restringem a relação causal a uma estrutura fixa de equações e (b) não estão adaptados à modelagem não paramétrica dos efeitos. A partir da proposição dos autores, a especificação geral dos efeitos direto, indireto e total de uma variável de tratamento sobre a variável dependente é expressa por:

$$
\begin{gathered}
\text { Efeito indireto: } \\
\begin{array}{c}
(t)=\mathrm{E}\left[Y_{i}\left(\mathrm{t}, \mathrm{M}_{i}(1)\right)-Y_{i}\left(\mathrm{t}, \mathrm{M}_{i}(0)\right)\right] \delta \\
\text { Efeito direto: } \\
(t)=\mathrm{E}\left[Y_{i}\left(1, \mathrm{M}_{i}(t)\right)-Y_{i}\left(0, \mathrm{M}_{i}(t)\right)\right] \zeta \\
\quad \text { Efeito total } \\
=\mathrm{E}\left[Y_{i}\left(1, \mathrm{M}_{1}(t)\right)-Y_{i}\left(0, \mathrm{M}_{0}(t)\right)\right] \tau
\end{array}
\end{gathered}
$$

Ou seja, o efeito total de uma variável de tratamento pode ser medido a partir da diferença entre o parâmetro estimado na presença de tratamento na equação que modela a variável dependente - no nosso caso, a equação (1) - e na equação que modela a variável

\footnotetext{
8 Para uma maior discussão sobre procedimento de estimação dos parâmetros das equações estruturais, consultar as notas de aula da disciplina "EC 571 Advanced Econometrics", ministrada pelo professor KuanPin Lin no Departamento de Economia da Universidade Estadual de Portland. Disponível em: <http://web.pdx.edu/ crkl/ec571/ec571.htm>. Acesso em: 19 mar. 2018.
} 
de mediação, equação (2), e o parâmetro estimado na ausência de tratamento nas duas equações.

Tingley et al. (2014) desenvolveram um pacote disponível para R cujos algoritmos de otimização para o cálculo dos efeitos apresentaram desempenho eficiente para funções tanto paramétricas quanto não paramétricas, mesmo sob a hipótese de interação entre as variáveis independentes na equação que estima a variável de mediação.

A fim de testarmos a robustez da hipótese que levantamos quanto aos efeitos das variáveis criminológicas sobre a satisfação com a democracia, estimamos três modelos de mediação causal, calculando os efeitos totais de cada uma das variáveis criminológicas. Para isso, tomamos a confiança interpessoal como variável de mediação, pois funciona como vetor para transmissão de efeitos indiretos, e adotamos modelos não paramétricos de estimação das equações. A especificação das equações estimadas é expressa por:

$$
\begin{aligned}
& \mathrm{S}=\mathrm{f}_{1}(I)+\mathrm{f}_{2}(P)+\mathrm{f}_{3}(G)+\mathrm{V}+\mathrm{u} \\
& \mathrm{I}=\mathrm{g}_{1}(P)+\mathrm{g}_{2}(G)+\mathrm{V}+\mathrm{u}
\end{aligned}
$$

em que $f_{i}$ e $g_{i}$ são funções que modelam as variáveis. Como a vitimização é uma variável binária, não é necessário que ela seja modelada com alguma função. Na especificação dos modelos não paramétricos, numa tentativa de parcimônia, eliminamos as variáveis de controle dos modelos.

$\mathrm{Na}$ seção seguinte, apresentamos a implementação dos modelos propostos. Adotamos a mesma sequência apresentada nesta seção - do modelo menos complexo e mais restrito, quanto à definição de uma estrutura causal entre as variáveis, para o mais complexo e mais generalista.

\section{Resultados dos testes da hipótese}

\section{Análises de regressão linear}

Na Tabela 1, podemos observar o resultado da estimação da equação (1), que modela a variável satisfação com a democracia. Dentre o grupo das variáveis criminológicas, a confiança na punição e a percepção de segurança foram estatisticamente significativas, ao passo que a vitimização não. Nessa dinâmica, confiança na punição apresentou grande relevância para a predição dos valores de satisfação com a democracia: foi a variável que apresentou maior coeficiente padronizado - 0,21. Como esperado, a confiança interpessoal, variável de mediação para os efeitos indiretos, também se revelou significativa no modelo. 
Tabela 1

Análise de regressão linear. Variável dependente: satisfação com a democracia - Brasil - 2014

\begin{tabular}{|l|c|c|c|}
\hline Variáveis & $\hat{\boldsymbol{B}}$ & $\boldsymbol{\beta}$ & $\mathbf{p}$-valor \\
\hline Intercepto & 1,08 & 0,00 & $0,00 * * *$ \\
\hline Confiança & 0,10 & 0,13 & $0,00 * * *$ \\
\hline Confiança na punição & 0,10 & 0,21 & $0,00 * * *$ \\
\hline Percepção de segurança & 0,05 & 0,08 & $0,00 * * *$ \\
\hline Vitimização & $-0,02$ & $-0,01$ & 0,67 \\
\hline Sexo & 0,03 & 0,02 & 0,38 \\
\hline Idade & $-0,00$ & $-0,02$ & 0,59 \\
\hline Cor & $-0,06$ & $-0,04$ & 0,10 \\
\hline Renda & $-0,01$ & $-0,02$ & 0,53 \\
\hline Escolaridade & $-0,01$ & $-0,08$ & $0,01 * *$ \\
\hline
\end{tabular}

Fonte: Elaboração dos autores com dados do Barômetro das Américas, Brasil, 2014. $\mathrm{N}=1388, \mathrm{R} 2$ ajustado $=0,09 ; * * * \mathrm{p}$-valor $\leq 0,00 ; * * \mathrm{p} \leq 0,01 ; * \mathrm{p} \leq 0,05$; sem estrelas: não significativo.

Na Tabela 2, que estima a variável de mediação da hipótese proposta, podemos observar que todas as variáveis criminológicas foram significativas para predição dos valores de confiança interpessoal.

Tabela 2

Análise de regressão linear. Variável dependente: confiança interpessoal - Brasil - 2014

\begin{tabular}{|l|c|c|c|}
\hline \multicolumn{1}{|c|}{ Variáveis } & $\hat{\boldsymbol{B}}$ & $\boldsymbol{\beta}$ & $\mathbf{p}$-valor \\
\hline Intercepto & 1,25 & 0,00 & $0,00 * * *$ \\
\hline Confiança na punição & 0,06 & 0,08 & $0,00 * * *$ \\
\hline Percepção de segurança & 0,10 & 0,12 & $0,00 * * *$ \\
\hline Vitimização & $-0,13$ & $-0,05$ & $0,04 *$ \\
\hline Sexo & $-0,08$ & $-0,05$ & 0,07 \\
\hline Idade & 0,00 & 0,05 & 0,11 \\
\hline Cor & 0,03 & 0,02 & 0,53 \\
\hline Renda & 0,02 & 0,05 & 0,11 \\
\hline Escolaridade & $-0,01$ & $-0,03$ & 0,34 \\
\hline
\end{tabular}

Fonte: Elaboração dos autores com dados do Barômetro das Américas, Brasil, 2014.

$\mathrm{N}=1389, \mathrm{R}^{2}$ ajustado $=0,04 ; * * * \mathrm{p}$-valor $\leqslant 0,00, * * \mathrm{p} \leqslant 0,01, * \mathrm{p} \leqslant 0,05$; sem estrelas: não significativo. 


\section{Modelo de equações simultâneas}

Conforme os motivos já mencionados, a estimação separada das equações (1) e (2) que modelam, respectivamente, a satisfação com a democracia e a confiança interpessoal gera problemas de heterocedasticidade, derivados da correlação dos resíduos das duas equações. Uma solução para estimar e interpretar o coeficiente das variáveis independentes, tal como a intensidade dos efeitos lineares diretos e indiretos das variáveis criminológicas, de forma robusta é a comparação entre os resultados identificados com as análises de regressão e os de um modelo de equações simultâneas (SEM).

$\mathrm{Na}$ Tabela 3, podemos verificar alterações relevantes nos coeficientes. De forma geral, os coeficientes dos preditores de satisfação com a democracia mantiveram a significância estatística. Esse resultado corrobora as expectativas geradas a partir das evidências levantadas por Tversky e Kahneman (1973) e Slovic, MacGregor e Kraus (1987) acerca dos mecanismos de influência da violência sobre o comportamento dos indivíduos. As duas variáveis significativas - confiança na punição e percepção de segurança referem-se a elementos heurísticos que concatenam informação sobre risco e ameaça de diversas fontes, para além da experiência direta do indivíduo, os quais, na formação de opiniões e atitudes, têm peso preponderante. Contudo, quanto à intensidade dos efeitos das variáveis, podemos identificar uma redução expressiva do peso da confiança na punição no condicionamento dos valores da variável dependente. Apesar de se manter como principal preditora, podemos inferir que parte dos efeitos identificados na Tabela 1 é derivada da endogeneidade do modelo.

Quanto aos preditores da confiança interpessoal, a significância estatística das variáveis permaneceu a mesma, contudo também houve uma alteração importante no valor dos coeficientes. A vitimização teve seu impacto acentuado, passando a desempenhar o maior efeito sobre os valores de confiança interpessoal, com isso, oferecendo maiores evidências para a tese da socialização. A vitimização compõe o universo de experiências das pessoas, sendo, portanto, capaz de gerar alterações nos componentes não racionalizáveis do comportamento, ou seja, induzir adoção de hábitos de forma não intencional. Quanto aos efeitos agregados das variáveis criminológicas, encontramos grande preponderância dos efeitos diretos - estimados em 0,135 desvio-padrão - em comparação aos efeitos indiretos - 0,003 desvio-padrão - na predição dos valores de satisfação com a democracia.

$\mathrm{Na}$ hipótese proposta, a violência tem um duplo efeito sobre a satisfação com a democracia: um efeito direto, na medida em que reduz os benefícios socioeconômicos providos pelo regime, e um indireto, na medida em que reduz a predisposição para formação de confiança interpessoal - uma das bases comportamentais fundamentais da adesão à democracia. O cálculo dos efeitos SEM permite comparar os dois efeitos e, no que diz respeito ao apoio instrumental ao regime, mensurado pela satisfação com a democracia, os efeitos diretos dominam a dinâmica. 


\section{Tabela 3 \\ Modelo de equações simultâneas (SEM) \\ Brasil - 2014}

\begin{tabular}{|c|c|c|c|}
\hline Variáveis dependentes & Variáveis independentes & $\boldsymbol{\beta}$ & p-valor \\
\hline \multicolumn{4}{|l|}{ Satisfação com a democracia } \\
\hline & Confiança & 0,096 & $0,00 * * *$ \\
\hline & Confiança na punição & 0,103 & $0,00 * * *$ \\
\hline & Percepção de segurança & 0,050 & $0,00 * * *$ \\
\hline & Vitimização & $-0,019$ & 0,68 \\
\hline & Sexo & 0,029 & 0,38 \\
\hline & Idade & $-0,001$ & 0,59 \\
\hline & Cor & $-0,058$ & 0,09 \\
\hline & Renda & $-0,006$ & 0,49 \\
\hline & Escolaridade & $-0,013$ & $0,01 * *$ \\
\hline \multicolumn{4}{|l|}{ Confiança } \\
\hline & Confiança na punição & 0,058 & $0,00 * * *$ \\
\hline & Percepção de segurança & 0,105 & $0,00 * * *$ \\
\hline & Vitimização & $-0,131$ & $0,04 *$ \\
\hline & Sexo & $-0,084$ & 0,08 \\
\hline & Idade & $-0,003$ & 0,11 \\
\hline & Cor & 0,032 & 0,53 \\
\hline & Renda & 0,020 & 0,12 \\
\hline & Escolaridade & $-0,007$ & 0,33 \\
\hline
\end{tabular}

Fonte: Elaboração dos autores com base em dados do Barômetro das Américas, Brasil, 2014. $\mathrm{N}=1398, \mathrm{R}^{2}$ : satisfação com a democracia $=0,10 /$ confiança $=0,05$, efeito direto $=0,135$, efeito indireto $=0,003$, efeito total $=0,138 ; * * * p$-valor $\leqslant 0,00 ; * * p \leqslant 0,01 ; * p \leqslant 0,05$; sem estrelas: não significativo.

\section{Modelos não paramétricos}

Nas Tabelas 4 e 5 estão os resultados dos modelos não paramétricos, estimados por máxima verossimilhança. Os modelos incluem apenas as variáveis criminológicas e, portanto, pela natureza distinta da estimação e pela diferença quanto ao número de variáveis independentes que incluímos, a interpretação dos parâmetros do modelo e as inferências que podemos fazer a partir deles são distintas. Como os modelos não paramétricos que utilizamos não são lineares em todos os parâmetros, a estatística que mensura a relevância de uma variável para modelagem da variável dependente é o teste F. Vitimização, por ser variável binária, foi incluída como único coeficiente paramétrico no modelo. 
O teste $\mathrm{F}$ mensura a relevância das variáveis, levando em consideração a proporção de aumento na soma dos quadrados dos resíduos derivada da ausência de uma dada variável no modelo. Portanto, seu valor não depende apenas do efeito marginal, ou seja, o $\beta$, mas também do efeito total disseminado por meio da presença de multicolinearidade entre as variáveis dependentes. Além disso, o peso de uma variável para a capacidade preditiva de um modelo também depende do seu papel em contornar problemas de inferência estatística. A ausência de uma variável pode impedir que a função que relaciona variáveis independentes e dependente seja eficiente, pois, sem os condicionantes certos, o efeito das variáveis é medido incorretamente. Um exemplo clássico é a modelagem com dados em painel de países muito diferentes entre si. Nesse caso, a ausência de uma dummy para distinguir as observações por país impede que o modelo seja estimado corretamente.

$\mathrm{Na}$ Tabela 4, que mensura os preditores de satisfação com a democracia, a confiança interpessoal e a confiança na punição apresentam maior relevância no modelo, ao passo que a vitimização não se mostra significativa.

Tabela 4

Estimação por máxima verossimilhança Variável dependente: satisfação com a democracia - Brasil - 2014

\begin{tabular}{|l|c|c|c|}
\hline \multicolumn{4}{|c|}{ Coeficiente paramétrico } \\
\hline Variáveis & $\hat{B}$ & F & p-valor \\
\hline Vitimização & $-0,02$ & 0,32 & 0,58 \\
\hline \multicolumn{4}{|c|}{ Coeficientes não paramétricos } \\
\hline Variáveis & EDF & F & p-valor \\
\hline Confiança & 1,00 & 25,78 & $0,00^{* * *}$ \\
\hline Confiança na punição & 2,18 & 22,83 & $0,00 * * *$ \\
\hline Percepção de segurança & 1,00 & 6,41 & $0,01^{* *}$ \\
\hline
\end{tabular}

Fonte: Elaboração dos autores com base em dados do Barômetro das Américas, Brasil, 2014.

$\mathrm{N}=1398, \mathrm{R}^{2}=0,09 ; * * * \mathrm{p}$-valor $\leqslant 0,00 ; * * \mathrm{p} \leqslant 0,01 ; * \mathrm{p} \leqslant 0,05$; sem estrelas: não significativo.

$\mathrm{Na}$ Tabela 5, que mensura os preditores de confiança interpessoal, a confiança na punição e a percepção de segurança apresentaram peso preponderante. Novamente, a vitimização revelou-se significativa como condicionante dos efeitos indiretos, mediados pela confiança. 


\section{Tabela 5 \\ Estimação por máxima verossimilhança Variável dependente: confiança interpessoal - Brasil - 2014}

\begin{tabular}{|l|c|c|c|}
\hline \multicolumn{5}{|c|}{ Coeficiente paramétrico } \\
\hline Variáveis & $\hat{B}$ & F & p-valor \\
\hline Vitimização & $-0,14$ & 4,98 & $0,03^{*}$ \\
\hline \multicolumn{4}{|c|}{ Coeficientes não paramétricos } \\
\hline Variáveis & EDF & F & p-valor \\
\hline Confiança na punição & 1,00 & 9,21 & $0,00 * * *$ \\
\hline Percepção de segurança & 2,14 & 10,41 & $0,00 * * *$ \\
\hline
\end{tabular}

Fonte: Elaboração dos autores com base em dados do Barômetro das Américas, Brasil, 2014. $\mathrm{N}=1398, \mathrm{R}^{2}=0,04 ; * * * \mathrm{p}$-valor $\leqslant 0,00 ; * * \mathrm{p} \leqslant 0,01 ; * \mathrm{p} \leqslant 0,05 ;$ sem estrelas: não significativo.

Em comparação aos modelos lineares, os modelos não paramétricos sugeriram duas conclusões adicionais: a confiança interpessoal apresenta propriedades estatísticas consoantes ao seu papel de variável de mediação e a confiança na punição incorpora grande proporção dos efeitos diretos das variáveis criminológicas. No modelo SEM, os efeitos da confiança interpessoal e da confiança na punição rivalizavam, contudo, levando em consideração efeitos não lineares, a primeira apresentando um papel preponderante em comparação à segunda. Isso ocorre, em grande medida, por ser a confiança interpessoal um indicador geral dos condicionantes que afetam a adesão à democracia bem como a avaliação dos elementos heurísticos de desempenho do regime: confiança na punição e percepção de segurança. Todavia, comparando confiança na punição e percepção de segurança, é possível identificar peso relativo significativamente maior em favor da primeira.

\section{Modelos de mediação causal}

O modelo de mediação causal proposto por Imai, Keele e Tingley (2010) permite realizar inferência quanto aos efeitos diretos, indiretos e totais das variáveis criminológicas sobre a satisfação com a democracia, de modo semelhante ao que realizamos, de forma mais restrita, com o modelo SEM. Para mensurar o efeito causal das variáveis criminológicas, utilizamos o modelo apresentado na Tabela 3 como modelo geral e o apresentado na Tabela 4 como modelo de mediação. O primeiro refere-se à equação que associa preditores de satisfação com a democracia como variável dependente. O segundo descreve a equação na qual a variável de tratamento projeta seus efeitos sobre a variável de mediação.

Esperamos que o modelo de Imai, Keele e Tingley (2010) apresente mensuração mais adequada dos efeitos das variáveis criminológicas sobre a satisfação com a democracia, pois estamos utilizando modelos não paramétricos, que possibilitam uma 
inferência mais generalista da causalidade e apresentam boa eficiência quanto ao tratamento da correlação entre os resíduos das equações (3) e (4).

Para identificar com maior precisão o vetor dos efeitos, construímos três modelos de mediação causal. Em cada um deles, uma das variáveis criminológicas foi eleita como variável de tratamento. A variável de mediação é a mesma para os três modelos: confiança interpessoal.

\section{Tabela 6 \\ Modelo de mediação causal. Variável de tratamento: Vitimização - Brasil - 2014}

\begin{tabular}{|l|c|c|}
\hline Efeito & $\hat{\boldsymbol{B}}$ & $\mathbf{p}$-valor \\
\hline Efeito mediado & $-0,0134$ & $0,02 *$ \\
\hline Efeito direto & $-0,0250$ & 0,60 \\
\hline Efeito total & $-0,0383$ & 0,52 \\
\hline Proporção mediada & 0,3482 & 0,50 \\
\hline
\end{tabular}

Fonte: Elaboração dos autores com base em dados do Barômetro das Américas, Brasil, 2014.

$\mathrm{N}=1398 ; * * * \mathrm{p}$-valor $\leqslant 0,00 ; * * \mathrm{p} \leqslant 0,01 ; * \mathrm{p} \leqslant 0,05 ;$ sem estrelas: não significativo.

$\mathrm{Na}$ Tabela 6, podemos identificar os resultados dos modelos de mediação causal para a variável de tratamento vitimização. Convergindo para os resultados anteriores, a vitimização apresentou efeito mediado - ou indireto - significativo. Contudo, com um pvalor elevado para efeito direto, o resultado é que o efeito total da vitimização sobre a satisfação com a democracia não é significativo, ou seja, o efeito da variável sobre a variável dependente não é significativo.

$\mathrm{Na}$ Tabela 7 estão os resultados do modelo de mediação causal para confiança na punição. Nos modelos lineares e também nos modelos não paramétricos essa variável apresentou grande poder preditivo sobre os valores de satisfação com a democracia. Todavia, encontramos evidências de que esse peso da variável sobre o apoio ao regime é fundamentalmente mobilizado por mecanismos diretos, na medida em que o efeito mediado não se revelou significativo no modelo estimado ao passo que o efeito direto apresentou grande significância, dominando a relação causal e propiciando efeito total também significativo. 
Tabela 7

Modelo de mediação causal Variável de tratamento: confiança na punição - Brasil - 2014

\begin{tabular}{|l|c|c|}
\hline Efeito & $\hat{\boldsymbol{B}}$ & $\mathbf{p}$-valor \\
\hline Efeito mediado & 0,00565 & 0,30 \\
\hline Efeito direto & 0,15561 & $0,00 * * *$ \\
\hline Efeito total & 0,16125 & $0,00 * * *$ \\
\hline Proporção mediada & 0,03503 & 0,30 \\
\hline
\end{tabular}

Fonte: Elaboração dos autores com base em dados do Barômetro das Américas, Brasil, 2014.

$\mathrm{N}=1398 ; * * * \mathrm{p}$-valor $\leqslant 0,00 ; * * \mathrm{p} \leqslant 0,01 ; * \mathrm{p} \leqslant 0,05 ;$ sem estrelas: não significativo.

Na Tabela 8, podemos observar as estimativas dos efeitos causais da percepção de segurança sobre a satisfação com a democracia. Assim como no caso da confiança na punição, o efeito mediado não se revelou significativo, ao passo que o efeito direto apresentou grande significância, o que tornou o efeito total também significativo.

Tabela 8

Modelo de mediação causal Variável de tratamento: percepção de segurança - Brasil - 2014

\begin{tabular}{|l|c|c|}
\hline Efeito & $\hat{\boldsymbol{B}}$ & $\mathbf{p}$-valor \\
\hline Efeito mediado & 0,00176 & 0,84 \\
\hline Efeito direto & 0,04507 & $0,00 * * *$ \\
\hline Efeito total & 0,04683 & $0,00 * * *$ \\
\hline Proporção mediada & 0,03756 & 0,84 \\
\hline
\end{tabular}

Fonte: Elaboração dos autores com base em dados do Barômetro das Américas, Brasil, 2014.

$\mathrm{N}=1398 ; * * * \mathrm{p}$-valor $\leqslant 0,00 ; * * \mathrm{p} \leqslant 0,01 ; * \mathrm{p} \leqslant 0,05 ;$ sem estrelas: não significativo.

De forma geral, os modelos de mediação causal destituíram algumas expectativas geradas a partir dos resultados dos modelos lineares e das estimações separadas dos modelos não paramétricos. Nesses últimos, percebemos grande poder preditivo da percepção de segurança e da confiança na punição sobre os valores de confiança interpessoal, a variável de mediação. Isso se mostrou, inicialmente, uma evidência de que os efeitos mediados ou indiretos seriam significativos. Contudo, dependendo da proporção da correlação entre os resíduos das equações (3) e (4), resultados significativos associados à variável de mediação podem apenas ser fruto de endogeneidade do modelo. As Tabelas 6, 7 e 8 oferecem um resultado final quanto à relação entre as variáveis criminológicas e a satisfação com a democracia: os efeitos diretos são preponderantes. Vale ressaltar, entretanto, que os modelos de mediação causal desagregam os efeitos das variáveis 
criminológicas, e isso pode ter sido responsável pela perda de significância dos efeitos indiretos.

\section{Conclusão}

Propomos, inicialmente, que a violência tem o potencial de reduzir o apoio à democracia na medida em que reduz os benefícios socioeconômicos propiciados pelo regime. Diante de uma proporção significativa de cidadãos brasileiros cuja adesão é mobilizada por mecanismos utilitários, é esperado um vetor direto de efeitos que associe vitimização, insegurança e desconfiança na justiça à satisfação com o sistema político vigente.

Além disso, uma potencial fonte indireta de consequências para o comportamento político dos indivíduos derivada da criminalidade diz respeito aos mecanismos cognitivos associados à expressão de altruísmo e à formação de cooperação. Na medida em que a violência põe em risco a segurança existencial dos cidadãos, há uma tendência de que eles adotem atitudes restritivas com relação à interação com outros indivíduos e, consequentemente, sejam mais resistentes ao processo de formação das bases socioculturais da democracia, as quais envolvem doses relevantes de confiança interpessoal.

As variáveis independentes que utilizamos, e sua respectiva alocação quanto à mensuração de cada tipo de efeito, foram a confiança na punição e a percepção de segurança - ambas associadas à violência e que possuem peso preponderante quanto à composição dos efeitos diretos - e a vitimização por crime - que, por mensurar uma experiência pessoal direta com o crime, tende a ser eleita como a principal fonte de efeitos indiretos.

Os resultados dos modelos de regressão linear, de equações simultâneas, bem como dos modelos não paramétricos, apresentaram evidências que corroboram a tese que construímos para a explicação do impacto da violência na satisfação com a democracia. Para mensurar efeitos diretos e indiretos adotamos um modelo estrutural com duas equações: uma que modela os valores de satisfação com a democracia, para mensurar o efeito direto, e uma que modela os valores de confiança, para mensurar o efeito indireto. Consonante com nossas expectativas, as variáveis percepção de segurança e confiança na punição foram significativas nas duas equações, ao passo que a vitimização apenas teve efeito significativo sobre confiança interpessoal.

Os modelos de mediação causal propostos por Imai, Keele e Tingley (2010) serviram de teste final para hipótese alimentada pelas evidências encontradas, sobretudo, no cálculo dos efeitos diretos, indiretos e totais realizados a partir dos coeficientes estimados pelo modelo SEM. A partir dos resultados dos modelos de mediação, a ideia de bivalência dos efeitos das variáveis criminológicas perdeu força: o vetor direto de impacto da violência é significativo, na medida em que confiança na punição e percepção de 
segurança compõem uma proporção robusta de efeitos, porém o vetor indireto, não, uma vez que a vitimização, única variável com impacto indireto significativo, perde sua significância como variável de tratamento pois o seu modelo não apresenta efeitos totais significativos.

De forma geral, o resultado dos modelos de mediação causal aponta informações importantes sobre a natureza dos dados estimados e desmente algumas inferências que podem ser realizadas a partir de correlações espúrias. A presença de grande covariância entre os resíduos das equações que mensuram, respectivamente, efeitos diretos e indiretos inflaciona os coeficientes associados a confiança na punição e percepção de segurança. Quando a heterocedasticidade é tratada, boas evidências surgem em prol da tese de que, no que diz respeito ao apoio instrumental ao regime - mensurado pela variável dependente principal utilizada, satisfação com a democracia -, os efeitos diretos compõem, fundamentalmente, os efeitos totais gerados pelas variáveis criminológicas, e que, por isso, a vitimização não é decisiva para a predição dos valores de satisfação com a democracia.

Devemos considerar, contudo, que, num aspecto mais amplo dos estudos sobre comportamento político, efeitos indiretos de variáveis criminológicas sobre a adesão à democracia não devem ser descartados. A adesão à democracia possui variantes importantes e os tipos de apoio podem ser distintos entre abstrato e instrumental. Trabalhos futuros podem investigar se o apoio difuso à democracia seria mais sensível a efeitos indiretos de variáveis criminológicas.

Marcio de Lucas Gomes - Departamento de Ciências Sociais, Universidade Federal do Ceará, Fortaleza, Ceará, Brasil. E-mail: <delucasmarcio@gmail.com>.

Jakson Alves de Aquino - Departamento de Ciências Sociais, Universidade Federal do Ceará, Fortaleza, Ceará, Brasil. E-mail: <marcioage@hotmail.com>.

\section{Referências bibliográficas}

Adorno, S. "Crime, justiça penal e desigualdade jurídica: as mortes que se contam no Tribunal do Júri". Revista USP, n²1, p. 132-151, 1994.

AXELROD, R.; HAMilton, W. D. "The evolution of cooperation". Science, vol. 211, n 4.489, p. 1.390$1.396,1981$.

BAQUERO, M. "Construindo uma outra sociedade: o capital social na estruturação de uma cultura política participativa no Brasil". Revista de Sociologia e Política, n 21, 2003.

BECKER, G. S. Crime and punishment: an economic approach. In: Fielding, N. G.; CLARKE, A.; WITT, R. (eds.). The economic dimensions of crime. New York: Springer, p. 13-68, 1968.

BRUS, W. Marketization and democratization: the Sino-Soviet divergence. In: BAGCHI, A. (ed.). Democracy and development. New York: Palgrave Macmillan, p. 256-281, 1995. 
BUNGE, M. "Systemism: the alternative to individualism and holism". The Journal of Socio-Economics, vol. $29, n^{\circ} 2$, p. 147-157, 2000.

CASALECCHI, G. "Legado democrático e atitudes democráticas na América Latina: efeitos diretos, indiretos e condicionais". Tese de doutorado, Universidade Federal de Minas Gerais, Belo Horizonte, 2016.

CerqueirA, D., et al. Atlas da violência. Brasília: Ipea, 2016.

Cheibub, J. A., et al. "What makes democracies endure?". Journal of Democracy, The Johns Hopkins University Press, vol. 7, $\mathrm{n}^{\circ} 1$, p. 39-55, 1996.

Coleman, J. S. Foundations of social theory. Cambridge: Harvard University Press, 1994.

COMERFORD, J. Saber viver em meio a encrenqueiros, valentões e perigosos. In: BARREIRA, C.; AQUINO, J. P.; SÁ, L. D. (orgs.). Violência, ilegalismos e lugares morais. Campinas: Pontes, p. 43-58, 2014.

DAWKINS, R. The selfish gene. Oxford: Oxford University Press, 1976.

EASTON, D. Uma teoria de análise política. Rio de Janeiro: Zahar, 1968.

Fernandez, K. E.; KUenzi, M. "Crime and support for democracy in Africa and Latin America". Political Studies, vol. 58, n 3, p. 450-471, 2010.

Giddens, A. A constituição da sociedade. São Paulo: Martins Fontes, 1989.

HAIR, J. F., et al. Análise multivariada de dados. Porto Alegre: Bookman Editora, 2009.

IMAI, K.; KeELE, L.; Tingley, D. "A general approach to causal mediation analysis". Psychological Methods, vol. 15, n 4, p. 309-334, 2010.

INGLEhART, R.; Welzel, C. Modernização, mudança cultural e democracia: a sequência do desenvolvimento humano. São Paulo: Francis, 2009.

LIPSET, S. M. "Some social requisites of democracy: economic development and political legitimacy". American Political Science Review, vol. 53, n 1, p. 69-105, 1959.

Lochner, K.; KAWACHI, I.; Kennedy, B. "Social capital: a guide to its measurement". Health and Place, vol. 5, n०4, p. 259-270, 1999.

LUNDÅSEN, S. "Podemos confiar nas medidas de confiança?". Opinião Pública, vol. 8, n 2, p. 304327, 2002.

MAZAR, N.; AMIR, O.; ARIELY, D. "The dishonesty of honest people: a theory of self-concept maintenance". Journal of Marketing Research, vol. 45, n 6, p. 633-644, 2008.

MoIsÉs, J. Á. Os brasileiros e a democracia: bases sociopolíticas da legitimidade democrática. São Paulo: Ática, 1995.

OHTSUKI, H., et al. "A simple rule for the evolution of cooperation on graphs and social networks". Nature, vol. 441, n० 7.092, p. 502-505, 2006.

OLSON, M. A lógica da ação coletiva: os benefícios públicos e uma teoria dos grupos sociais. São Paulo: Edusp, 1999.

PAIVA, L. F. A construção social do calvário: sobre como os meios de comunicação retratam mortes violentas. In: BARREIRA, C.; AQuino, J. P.; SÁ, L. D. (orgs.). Violência, ilegalismos e lugares morais. Campinas: Pontes, p. 135-156, 2014.

PINKER, S. Os anjos bons da nossa natureza: por que a violência diminuiu. São Paulo: Companhia das Letras, 2013.

PUTNAM, R. D. Making democracy work: civic traditions in modern Italy. Princeton, NJ: Princeton University Press, 1994. 
VIOLÊNCIA E SATISFAÇÃO COM A DEMOCRACIA NO BRASIL

REIS, B. P. W. "Capital social e confiança: questões de teoria e método". Revista de Sociologia e Política, n²1, p. 35-49, 2003.

ROEMER, J. E. On the relationship between economic development and political democracy. In: BAGCHI, A. (ed.). Democracy and development. New York: Palgrave Macmillan, p. 28-56, 1995.

SAPOLSKY, R. M. "Social status and health in humans and other animals". Annual Review of Anthropology, p. 393-418, 2004.

Slovic, P.; MACGRegor, D.; Kraus, N. N. "Perception of risk from automobile safety defects". Accident Analysis \& Prevention, vol. 19, n 5, p. 359-373, 1987.

TINGLEY, D., et al. "Mediation: r package for causal mediation analysis". Journal of Statistical Software, vol. 59, n 5, 2014.

Tomasello, M. The cultural origins of cognition. Cambridge, MA: Harvard University Press, 1999.

TVERSKY, A.; KAHNEMAN, D. "Availability: a heuristic for judging frequency and probability". Cognitive Psychology, vol. 5, n², p. 207-232, 1973.

Weber, M. A ética protestante e o espírito do capitalismo. São Paulo: Companhia das Letras, 2004.

Welzel, C.; INGlehart, R.; KRUSE, S. "Pitfalls in the study of democratization: testing the emancipatory theory of democracy". British Journal of Political Science, vol. 47, n 2, p. 463-472, 2017.

WiLSON, F. South Africa: the problems in a deeply divided society. In: BAGCHI, A. (ed.). Democracy and development. New York: Palgrave Macmillan, p. 235-253, 1995.

Wooldridge, J. M. Econometric analysis of cross section and panel data. Cambridge: MIT Press, 2010.

\section{Resumo}

Violência e satisfação com a democracia no Brasil

A democracia é um regime político que está relacionado não apenas ao cumprimento de procedimentos, mas também a valores e comportamentos. Uma de suas bases são redes de confiança interpessoal que fundamentam a cooperação entre indivíduos. Dado que o sistema democrático funciona como um mecanismo de resolução de problemas de ação coletiva, alocando recursos dos cidadãos para prover bens públicos, a satisfação de alguém com o regime envolve a percepção sobre as atitudes das outras pessoas, ou seja, se estão cooperando ou não para a sociedade. Além disso, a eficiência institucional também tem impacto sobre a opinião pública: democracias que não provêm bens públicos satisfatoriamente tendem a contar com menor apoio popular. Neste artigo, investigamos os efeitos de variáveis criminológicas sobre a satisfação com a democracia no Brasil, testando a hipótese quanto à presença de duplo vetor de efeitos: um direto - reduzindo apoio instrumental ao regime - e outro indireto - reduzindo confiança interpessoal. Para isso, utilizamos dados do Barômetro das Américas, de 2014. Testes feitos com modelos de regressão linear, equações simultâneas e modelos não paramétricos corroboraram a hipótese. Entretanto, modelos de mediação causal, uma forma mais rigorosa de testar a hipótese, revelaram não haver efeitos indiretos significativos.

Palavras-chave: violência; satisfação com a democracia; Brasil; efeitos diretos e indiretos 


\begin{abstract}
Violence and satisfaction with democracy in Brazil

Democracy is a political regime characterized both by the use of non-violent procedures to choose leaders, and by the democratic values and attitudes of its people. Democracy is based on interpersonal trust that ensures cooperation between individuals. Democratic systems function as a way of solving collective action problems by allocating citizens' resources to promote public benefits. Hence, an individual's satisfaction with the regime depends on the perception of other people as a cooperative. Moreover, institutional efficiency has an impact on public opinion; democracies that do not produce enough public goods tend to receive less support from their populations. In this article, we investigate the effects of criminological variables on satisfaction with democracy in Brazil, testing the hypothesis that there is both a direct effect-reducing instrumental support of the regime-and an Indirect effectreducing interpersonal trust. We test this hypothesis with data from the 2014 AmericasBarometer. Tests conducted via linear regression models, simultaneous equations, and non-parametric models corroborate this hypothesis. However, causal mediation models, a more rigorous way of testing this hypothesis, revealed no significant indirect effects.
\end{abstract}

Keywords: violence; satisfaction with democracy; Brazil; direct and indirect efects

\title{
Resumen
}

Violencia y satisfacción con la democracia en Brasil

La democracia es un régimen político que está relacionado no sólo al cumplimiento de procedimientos, sino también a valores y comportamientos. Una de sus bases son las redes de confianza interpersonal que fundamentan la cooperación entre los individuos. En la medida que el sistema democrático funciona como un mecanismo de resolución de problemas de acción colectiva, designando los recursos de los ciudadanos para fomentar bienes públicos, la satisfacción de alguien con el régimen incluye la percepción sobre las actitudes de las otras personas, o sea, si están cooperando o no para la sociedad. Además, la eficiencia institucional también tiene impacto sobre la opinión pública: democracias que no producen bienes públicos en nivel satisfactorio tienden a tener menos apoyo de la población. En este artículo, investigamos los efectos de las variables criminológicas sobre la satisfacción con la democracia en Brasil, probando la hipótesis de la presencia de un efecto directo -reducir el apoyo instrumental al régimen- y un efecto indirecto -reduciendo la confianza interpersonal. Usamos datos del Barómetro de las Américas 2014. Las pruebas realizadas con modelos de regresión lineal, ecuaciones simultáneas y modelos no paramétricos corroboraron la hipótesis. Sin embargo, los modelos de mediación causal, una forma más rigurosa de probar la hipótesis, no revelaron efectos indirectos significativos.

Palabras clave: violencia; satisfacción con la democracia; Brasil; efectos directo e indirecto

\section{Résumé}

La violence et la satisfaction à l'égard de la démocratie au Brésil

La démocratie est un régime politique caractérisé par le respect de certaines procédures, ainsi que par les valeurs et les attitudes démocratiques. La démocratie repose sur la confiance interpersonnelle qui assure la coopération entre les individus. Les systèmes démocratiques fonctionnent comme un moyen de résoudre les problèmes d'action collective en allouant les ressources des citoyens pour promouvoir les avantages publics. Par conséquent, la satisfaction des individus à l'égard du régime dépend de la perception sur les attitudes des autres personnes, c'est-à-dire si elles coopèrent ou non avec la société. En outre, l'efficacité institutionnelle a un impact sur l'opinion publique. Les démocraties qui ne produisent pas suffisamment de biens publics ont tendance à recevoir moins de soutien de leur population. Dans cet article, nous étudions les effets des variables criminologiques sur la satisfaction envers la démocratie au Brésil, en testant l'hypothèse de la présence d'un effet direct - réduction du soutien instrumental au régime - et d'un effet indirect - réduction de la confiance interpersonnelle. 
VIOLÊNCIA E SATISFAÇÃO COM A DEMOCRACIA NO BRASIL

Nous utilisons les données du Baromètre des Amériques 2014. Des tests effectués avec des modèles de régression linéaire, des équations simultanées et des modèles non paramétriques corroborent cette hypothèse. Cependant, les modèles de médiation causale, une façon plus rigoureuse de tester I'hypothèse, n'ont révélé aucun effet indirect significatif.

Mots clés: violence; satisfaction à l'égard de la démocratie; Brésil; effects direct et indirect

Artigo submetido à publicação em 12 de abril de 2017. Versão final aprovada em 7 de março de 2018. 